\title{
Investigation of the effect of gestational diabetes on fetal cardiac tissue in streptozotocin induced in rats ${ }^{1}$
}

Ugur Turhan', Ercan Yilmaz", Mehmet Gul'"', Rauf Melekoglu'v, Yusuf Turkoz , Fatma Ozyalin', Hakan Parlakpinar ${ }^{\mathrm{VII}}$, Yavuz Simsek ${ }^{\mathrm{VIII}}$

'MD, Department of Obstetrics and Gynecology, Faculty of Medicine, Health Science University, Kanuni Sultan Suleyman Education and Research Hospital, Istanbul, Turkey. Conception and design of the study.

"Associate Professor, Department of Obstetrics and Gynecology, Faculty of Medicine, Inonu University, Malatya, Turkey. Manuscript writing.

I'Full Professor, Department of Histology and Embriyology, Faculty of Medicine, Inonu University, Malatya, Turkey. Histopathological examinations.

IVAssistant Professor, Department of Obstetrics and Gynecology, Faculty of Medicine, Inonu University, Malatya, Turkey. Acquisition of data.

${ }^{\vee}$ Full Professor, Department of Biochemistry, Faculty of Medicine, Inonu University, Malatya, Turkey. Technical procedures. V'MD, Department of Biochemistry, Faculty of Medicine, Inonu University, Malatya, Turkey. Statistical analysis.

VIIFull Professor, Department of Pharmacology, Faculty of Medicine, Inonu University, Malatya, Turkey. Critical revision.

VIIIAssociate Professor, Private Clinic, Kırıkkale, Turkey. Manuscript preparation.

\section{Abstract}

Purpose: To investigate the cause of congenital anomalies resulted from gestational diabetes on fetal cardiac tissue in experimental animal study model.

Methods: Totally 12 female Wistar albino rats were divided into two groups, each consisting of 6 rats. Streptozotocin $(60 \mathrm{mg} / \mathrm{kg}$ ) was administered intraperitoneally to the study group by dissolving in citrate solution. The rats with a blood glucose level of $200 \mathrm{mg} / \mathrm{dL}$ and above were considered to be diabetic rats. Total antioxidant status (TAS), total oxidative stress (TOS) and oxidative stress index (OSI) values were calculated in the cardiac tissues and maternal serum samples of the fetuses delivered by cesarean section after the mating process. The cardiac tissues were also subjected to histopathological examination.

Results: TOS and OSI values in fetal cardiac tissues of the diabetic rats were found to be significantly higher than that of the control group ( $p=0.026$ and $p=0.005)$. Histopathological examination revealed that the mitotic index was lower and the cell organization was found to be damaged in the fetuses of the study group rats.

Conclusion: Increased levels of free oxygen radicals considered to be due to hyperglycemia may cause congenital anomalies, especially during organogenesis period, by disrupting cell homeostasis and adversely affecting mitosis.

Key words: Antioxidants. Oxidative Stress. Hyperglycemia. Diabetes, Gestational. Rats. 


\section{Introduction}

Diabetes Mellitus (DM) is a chronic and multisystemic disease, characterized by glucose intolerance, and multiple mechanisms are responsible in its etiology. Another variant of this chronic disease, which can be explained by insufficient serum insulin level and/or the development of resistance to the insulin function in target tissues, is gestational diabetes (GDM) caused by altered hormone and metabolic status arising in pregnant women. Maternal hyperglycemia arising during pregnancy has been associated with fetal macrosomia, neonatal hypoglycemia, especially cardiac congenital anomalies and increased fetal mortality ${ }^{1}$. At the same time, diabetic pregnant women also have increased the risk of hypertension, infection, cesarean section and operative delivery ${ }^{2}$.

Although the etiology of GDM has not been fully understood, studies have shown that increased oxidative stress due to maternal hyperglycemia caused the development of fetal and maternal complications. Reactive oxygen radicals (ROR) result in the development of oxidative stress, and in cases where antioxidant mechanisms are insufficient, they lead to functional alteration or damage in structural patterns such as lipid, protein and DNA, at cellular level. It is known that this condition causes cellular damage by disrupting the sensitive balance in the cell cycle and leads to some congenital malformations characterized by $\mathrm{GDM}^{3}$.

In order to obtain an objective value in studies conducted on this topic, total oxidant status (TOS) is used to assess the elevated levels of free oxygen radicals caused by maternal hyperglucosemia due to uncontrolled GDM and likewise, total antioxidant status (TAS) value is used to assess the levels of substrates in enzymatic and non-enzymatic antioxidant defense mechanisms. The oxidative stress index (OSI, TOS/TAS), which is more specific than the TOS and TAS values and assesses the oxidative state of cells more sensitively, is another marker used for this purpose ${ }^{4}$.

We aimed to investigate the effect of hyperglycemia on fetal cardiac tissue by assessing the TAS, TOS, OSI and cardiac cell microscopy in the cardiac tissue and maternal serum of fetuses of female Wistar albino rats that were made diabetic by the administration of streptozotocin (STZ).

\section{Methods}

After obtaining Ethics Committee approval from Inonu University, 12 weeks old 12 female Wistar albino rats, approximately 200-300 gr in weight, were used in this study which was conducted by researchers with the certificate for the use of laboratory animals. After all rats were evaluated to be healthy under veterinary control, they were placed in the laboratory environment and kept for approximately 14 days for adaptation period to the environment. The standard environment in plastic cages was designed in the form of 12 hours of daytime and 12 hours of nighttime periods. The room temperature was $20^{\circ} \mathrm{C}$ and humidity level was kept in the range of 40 and $60 \%$. Animals access to dry fodder was standard and feeding was provided in the form of ad libitum and water was provided with tap water until the end of the study. The study was conducted in accordance with the principles of the Declaration of Helsinki for animal experiments.

\section{Preparation of experimental animals}

STZ (60 $\mathrm{mg} / \mathrm{kg}$ ) was administered intraperitoneally by dissolving in citrate solution in order to produce diabetes in rats. Rats with a blood glucose level of $200 \mathrm{mg} / \mathrm{dL}$ and above were considered to be diabetic ${ }^{5}$. 
Our study was designed in the form of 2 groups and 12 rats, 6 in each group, were used and 2 rats in both groups were excluded from the study since pregnancy could not be obtained. The next morning after mating, vaginal smear samples were taken and the presence of sperm in light microscopy was determined to be the $0^{\text {th }}$ day of pregnancy. The weight gain, blood glucose levels, fluid intake and consumption of maternal rats were monitored regularly in the diabetic group and the control group over the course of their pregnancies. Following the $20^{\text {th }}$ day of pregnancy, abdomens were opened by cesarean incision and the fetuses were delivered in both groups.

The number of abortion, number of newborn fetuses, weight, crown rump lenght (CRL) placental weight and possible congenital anomalies were evaluated in the diabetic group and in the control group. In newborn rats, cardiac tissues were excised by making a thoracic incision and then cardiac tissue was weighed. The cellular and nuclear alterations, mitotic index were assesed immunhistochemically in the newborn cardiac tissue by using electron microscope. Also TAS, TOS and OSI levels were assayed biochemically. Oxidative stress caused by maternal diabetes has also been studied in maternal centrifuged serum.

\section{Measurement of blood samples}

During the study blood samples, after the delivery of newborns, maternal cardiac blood samples were taken. Blood glucose concentration was determined by enzymatic assay of glucose oxidase (Ames GlucometerMiles Laboratories Inc., Elkhart, IN, USA)

Preparation of tissue supernatants and serum samples

$0.9 \mathrm{ml}$ of sodium phosphate buffer
$(\mathrm{pH}: 7$ and $100 \mathrm{mM})$ was added on $0.1 \mathrm{gr}$ of fetal cardiac tissue, and then it was subjected to 3 -min homogenization at $14,000 \mathrm{rpm}$ in ice. Thus, $10 \%$ homogenate was prepared. This homogenate was then centrifuged at 3500 rpm at +4 으 for $15 \mathrm{~min}$ and the supernatants were obtained. Blood samples were taken from the maternal rats between 8-10 o'clock in the morning and the serums were separated. These supernatant and serum samples were used for TAS and TOS measurements.

\section{Measurement of TAS}

Plasma and tissue TAS levels were determined using a commercially available kit developed by Erel ${ }^{6}$, (REL assay diagnostics, Mega Tip, Gaziantep, Turkey). In this method, hydroxyl radical, which is the most potent radical, is produced via Fenton reaction. In the classical Fenton reaction, the hydroxyl radical is produced by mixing of ferrous ion solution and hydrogen peroxide solution. In the most recently developed assay by Erel, the same reaction is used. In the assay, ferrous ion solution, which is present in the reagent 1 , is mixed with hydrogen peroxide, which is present in the reagent 2 . The sequentially produced radicals such as brown-colored dianisidinyl radical cation, produced by the hydroxyl radical, are also potent radicals. In this assay, antioxidative effect of the sample against the potent-free radical reactions, which is initiated by the produced hydroxyl radical, is measured ${ }^{7}$. The assay has got excellent precision values which are lower than $3 \%$. The results are expressed as millimoles of Trolox (Sigma-Aldrich Chemical Co., Deutschland, Germany) equivalent per liter.

\section{Measurement of TOS}

Plasma and tissue TOS levels were determined using a commercially available 
kit, developed by $\operatorname{Erel}^{6}$ (REL assay diagnostics, Mega Tip, Gaziantep, Turkey). In this method, oxidants present in the sample oxidize the ferrous ion-odianisidine complex to ferric ion. The oxidation reaction is enhanced by glycerol molecules, which are abundantly present in the reaction medium. The ferric ion makes a colored complex with xylenol orange in an acidic medium. The color intensity, which can be measured spectrophotometrically, is related to the total amount of oxidant molecules present in the sample ${ }^{7}$. The assay is calibrated with hydrogen peroxide, and the results are expressed in micromolar hydrogen peroxide $\left(\mathrm{H}_{2} \mathrm{O}_{2}\right)$ equivalent per liter $\left(\mu \mathrm{mol} \mathrm{H}_{2} \mathrm{O}_{2}\right.$ equiv/L) and and other derivatives of peroxides, produced physiologically in organisms and occurring in higher concentrations in the tissues under some pathologic conditions, and diffuse into plasma. The level of total peroxide was measured and expressed as TOS in this study.

\section{Measurement of OSI}

The ratio of TOS to TAS was accepted as the OSI. For calculation, the resulting unit of TAS was converted to $\mathrm{mol} / \mathrm{L}$, and the OSI value was calculated according to the following formula; OSI (arbitrary unit) $=\mathrm{TOS}\left(\mathrm{mmol} \mathrm{H}_{2} \mathrm{O}_{2}\right.$ equiv/L)/TAC (mmol Trolox equiv/L) ${ }^{6}$.

\section{Histologic examination}

All the specimens were also sent for histologic investigation in order to confirm the tissue diagnosis. For light microscopic evaluation, neonatal heart and brain samples were mixed in phosphate buffered $10 \%$ formalin and prepared for routine paraffin embedding. Sections of tissues were cut at $5 \mu \mathrm{m}$, mounted on slides, stained with hematoxylin and eosin (H\&E) and examined by a Leica DFC280 light microscope and Leica Q Win Image Analyses
System (Leica Microsystems Imaging Solutions, Cambridge, UK). Tissue sections were then examined microscopically by a pathologist blind to clinical data and experimental procedure. The major histopathological findings of cellular damage, vacuolation, necrosis, vascularity and leucocyte infiltration were evaluated. The histological score of the organ was calculated as the sum of the scores (0-3) given for each criterion, using the semiquantitative scale. Histological scorings were made at magnification of $40 \mathrm{f}$ from 20 random fields per section from each specimen.

\section{Statistical analysis}

Statistical analysis of the data was made using the SPSS version 15.0 software for Windows. The data was checked by the Kolmogorov-Smirnov test for normal distribution. The independent samples t-test (morphometric findings, blood TOS level, tissue OSI level) was used for the comparison of normally distributed parameters, the MannWhitney $U$ test and Fisher's exact test were used for the comparison of non-normally distributed and categorical parameters (blood TAS, tissue TAS, tissue TOS, blood OSI and mitotic index) without normal distribution. A value of $P<0.05$ was accepted to be the limit of statistical significance.

\section{Results}

A total of 12 Wistar rats were divided into two groups, each consisting of 6 rats, and 6 rats that were made diabetic by the administration of STZ formed the study group. The mean blood glucose level of rats was $275(68-363) \mathrm{mg} / \mathrm{dL}$ in the study group and was $89(66-105) \mathrm{mg} / \mathrm{dL}$ in the control group . When the neonatal results were analyzed, the macrosomic effect of diabetes was clearly revealed in the study group (Table 1 ). 
Table 1 - Comparison of fetal morphometric results of diabetic and control groups. CRL: Crown-rumb length.

\begin{tabular}{lccc} 
& Control Group & Study Group & p \\
\hline Maternal blood glucose level (mg/dL) & $89(66-105)$ & $275(68-363)$ & $<0.001$ \\
CRL (mm) & $37 \pm 3.12$ & $39 \pm 4.46$ & 0.03 \\
Birth weight (g) & $4.1 \pm 1.65$ & $5.1 \pm 0.73$ & 0.007 \\
Placental weight (g) & $0.7 \pm 0.19$ & $0.9 \pm 0.24$ & 0.016 \\
Heart weight (g) & $0.2 \pm 0.04$ & $0.4 \pm 0.1$ & $<0.001$ \\
\hline
\end{tabular}

Cardiac blood samples of the rats delivered by cesarean section were analyzed for the assessment of TAS and TOS values. The mean TOS value was found to be $1.4 \pm 2.77$ in the study groupand $1.2 \pm 0.15 \mu \mathrm{mol}$ eq./L in the control group. When the maternal serum TAS values were analyzed, the TAS value was assessed to be $0.86 \pm 0.87 \mathrm{mmol}$ Trolox equivalent/L in diabetic rats and $0.58 \pm 2.53$ $\mathrm{mmol}$ Trolox equivalent/ $\mathrm{L}$ in the control group. The results of serum OSI were found to be 0.7 in the study group and 0.3 in the control group. When the results of maternal serum oxidant status were analyzed, it was found that the TOS and OSI values were higher in diabetic rats than in the control group but were not statistically significant.

Tissue TAS, TOS and OSI levels were assessed by measuring the cardiac tissues of fetuses delivered in the study and control groups at $530 \mathrm{~nm}$ with spectrophotometric method. The cardiac tissue TOS and OSI values were found to be statistically significantly higher in fetuses delivered from diabetic rats compared to the control group (Table 2).

Table 2 - Oxidative status parameters of fetal cardiac tissue. TAS: Total antioxidant status.

\begin{tabular}{lccc} 
& $\begin{array}{c}\text { Control Group } \\
(\mathbf{n = 2 8})\end{array}$ & $\begin{array}{c}\text { Study Group } \\
(\mathbf{n = 3 1 )}\end{array}$ & p \\
\hline $\begin{array}{l}\text { Cardiac tissue TAS } \\
\text { mmol Trolox equivalent/L }\end{array}$ & 0.21 & 0.28 & NS \\
$\begin{array}{l}\text { Cardiac tissue TOS } \\
\boldsymbol{\mu m o l ~ e q / L ~}\end{array}$ & 8.10 & 10.5 & 0.026 \\
Cardiac tissue OSI & 22.6 & 32.3 & 0.005 \\
\hline
\end{tabular}

TOS: Total oxidative status. OSI: Oxidative stress index. NS: Not significant.

The tissues taken from the fetal cardiac tissues were also histopathologically evaluated. Centrally-localized euchromatic nuclei and eosinophilic stained granularfilamentous cytoplasmic content were noted in cardiomyocytes oriented in different directions within the myocardial layer. Longitudinal sections showed typical transverse bandings and myofibril bundles in the cytoplasm of the cardiomyocytes. Cardiac tissue examination of fetuses delivered from the diabetic rats revealed that the nuclei of cardiomyocytes had a large, euchromatic structure and chromatolysis was present in some of the nuclei. In addition, cells with heterochromatic-pyknotic nucleus were seen in some areas. The cytoplasm of the cardiomyocytes generally contained edematous large vacuoles, cytoplasmic staining 
intensity was reduced and their borders were irregular the cytoplasm. Hydropic degeneration was detected in the cardiomyocytes in some areas within the myocardium. Typical regular myofibril organization was not observed in the cytoplasm of the cardiomyocytes. When the mitotic indices of both groups were calculated, the mitotic index of the control group $(1.22 \pm 0.28)$ was found to be significantly higher than that of the study group $(0.47 \pm 0.42)$ $(p=0.001)$.

The sections were found to have partial mitotic figures at reduced rate (Figure 1).

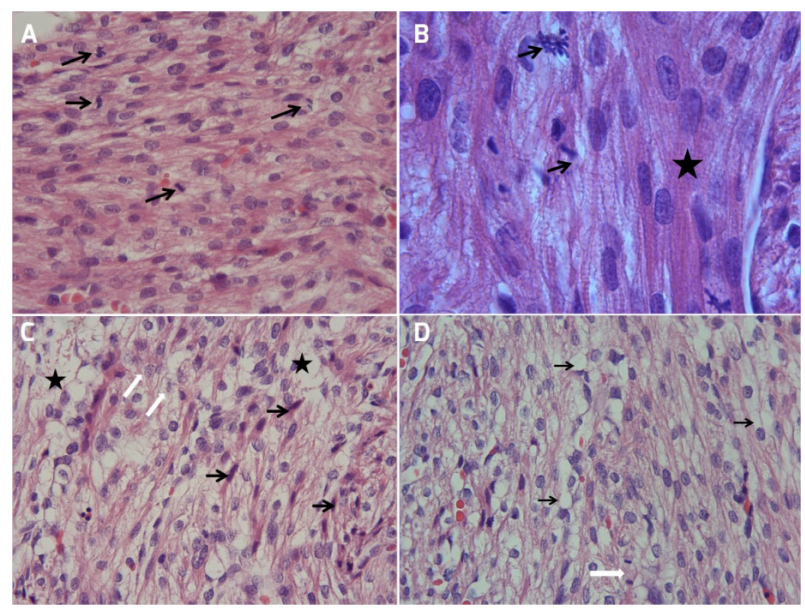

Figure 1 - Examination of the cardiac tissues of fetuses of Wistar rats included in the control and study groups with Hematoxylin-Eosin stain. A. Control group light microscopy (H\&E x40), black arrows demonstrate the mitotic figures. B. Group light microscopy (H\&E x100), black arrows demonstrate the mitotic figures, and the star-marked area demonstrates the transverse banding in cardiomyocytes. C. Gestational diabetes group, light microscopy (H\&E x40), black arrows demonstrate the pyknotic nucleus which is also the indicator of apoptosis, white arrows demonstrate the chromatolysis in nucleus, star symbol demonstrates the cytoplasmic hydropic alteration. D. Diabetes group, light microscopy (H\&E x40), black arrows demonstrate the cytoplasmic vacuolation, white arrows demonstrate the advanced stage mitotic figure.

\section{Discussion}

The mitosis and apoptosis microbalance, which forms the basis of the cell cycle, can be obtained by neutralizing the formed free oxygen radicals with enzymatic and/or nonenzymatic antioxidant activities. The impairment of this cell balance, which is essential for a healthy cell cycle, in favor of free oxygen radicals is associated with many pathological conditions, especially with the formation of tumorogenesis, leading to lipid peroxidation and DNA damage ${ }^{8}$. In studies conducted, the oxidative damage has been shown to have caused some congenital malformations, disrupting the structure of cell lipids, proteins, nucleic acids and hydrocarbons, especially affecting the development of tissue negatively during embryogenesis ${ }^{9}$. A study conducted by Pietryga et al. ${ }^{10}$ found that free oxygen radicals were significantly higher in the serum of women, who were found to have chromosomal anomaly and congenital fetal malformation, than that of the control group.

GDM is a chronic disorder, diagnosed during the second trimester of pregnancy and characterized by maternal hyperglycemia, leading to various congenital anomalies, especially cardiac malformations in fetus. It is believed that free oxygen radicals play a vital role in this regard, although it has still not been clearly understood how they cause congenital malformations. The levels of antioxidant enzymes and TAS value have been shown to be significantly lower in the serum of patients diagnosed with GDM than that of the control group $^{11}$.

In the literature, the fetal effects of hyperglycemia have been tried to be explained in animal models that were made diabetic by injecting STZ which causes direct damage in pancreatic $\beta$-cells. In a study conducted on Wistar rats that were experimentally made 
diabetic, the levels of antioxidant enzyme were found to be lower in fetuses found to have congenital anomaly than in the control group ${ }^{12}$. Similar results were also obtained in the study of Zhao et al. ${ }^{13}$, free oxygen radicals were found to be higher in the anomalous fetuses of diabetic rats in proportion to the level of hyperglycemia. An animal model study investigated the results of $\mathrm{N}$-acetylcysteine administration, an antioxidant derivative, in diabetic rats showed that serum superoxide levels were significantly reduced in diabetic animals received antioxidants, and that fetal cardiac cell proliferation was improved, and that myocardial tissue thickness increased significantly ${ }^{14}$.

Free oxygen radicals that form in fetuses of diabetic rats and are found at higher rates in other malformed organs, especially in cardiac organs, can be directly associated with these congenital malformations. Regular mitosis function, which is responsible for the development of healthy organs, especially during organogenesis period, does not function properly due to the direct effect of free radicals. These radicals directly affect the DNA structure of cell and cause mitotic arrest, which ultimately leads to cell vacuolation, chromatolysis and pyknotic nucleus development, negatively affecting the organogenesis ${ }^{15}$. In our study, we also encountered reduced mitotic indices inversely proportional to the increased free oxygen radical levels in the fetal cardiac tissues of diabetic rats.

\section{Conclusion}

Increased levels of free oxygen radicals considered to be due to hyperglycemia may cause congenital anomalies, especially during organogenesis period, by disrupting cell homeostasis and adversely affecting mitosis.

\section{References}

1. Yilmaz E, Celik O, Celik N, Celik E, Turkcuoglu I, Simsek Y, Minareci Y, Boz M, Aydin S. Maternal and fetal serum orexin-A levels in gestational diabetes mellitus. J Obstet Gynaecol Res. 2013;39:139-45. doi: 10.1111/j.1447-0756.2012.01955.x.

2. Rodrigues F, de Lucca L, Neme WS, Goncalves TL. Influence of gestational diabetes on the activity of $\delta$-aminolevulinate dehydratase and oxidative stress biomarkers. Redox Rep. 2017;17:1-5. doi: 10.1080/13510002.2017.1402981.

3. Baz B, Riveline JP, Gautier JF. Endocrınology of pregnancy. Gestational diabetes mellitus: definition, aetiological and clinical aspects. Eur J Endocrinol. 2016;174:43-51. doi: 10.1530/EJE-15-0378.

4. Usluogullari B, Usluogullari CA, Balkan F, Orkmez M. Role of serum levels of irisin and oxidative stress markers in pregnant women with and without gestational diabetes. Gynecol Endocrinol. 2017;33:405-7. doi: 10.1080/09513590.2017.1284789.

5. Thornberry NA, Rano TA, Peterson EP, Rasper DM, Timkey T, Garcia-Calvo M, Houtzager VM, Nordstrom PA, Roy S, Vaillancourt JP, Chapman KT, Nicholson DW. A combinatorial approach defines specificities of members of the caspase family and granzyme B. Functional relationships established for key mediators of apoptosis. J Biol Chem. 1997;272:17907-11. doi: 10.1074/ jbc.272.29.17907.

6. Simsek Y, Gul M, Yilmaz E, Ozerol IH, Ozerol $\mathrm{E}$, Parlakpinar $\mathrm{H}$. Atorvastatin exerts antinociceptive activity and decreases serum levels of high-sensitivity C-reactive protein and tumor necrosis factor- $\alpha$ in a rat endometriosis model. Arch Gynecol Obstet. 2014;290:999-1006. doi: 10.1007/s00404014-3295-4.

7. Karsen H, Binici I, Sunnetcioglu M, Baran Al, Ceylan MR, Selek S, Celik H. Association of paraoxonase activity and atherosclerosis in patients with chronic hepatitis B. Afr Health Sci. 2012;12:114-8. doi: 10.4314/ahs. v12i2.6.

8. Levine AS, Sun L, Tan R, Gao Y, Yang L, Chen $H$, Teng $Y$, Lan $L$. The oxidative DNA damage 
response: A review of research undertaken with Tsinghua and Xiangya students at the University of Pittsburgh. Sci China Life Sci. 2017;60:1077-80. doi: 10.1007/s11427017-9184-6.

9. Gęgotek A, Nikliński J, Žarković N, Žarković K, Waeg G, Łuczaj W, Charkiewicz R, Skrzydlewska E. Lipid mediators involved in the oxidative stress and antioxidant defence of human lung cancer cells. Redox Biol. 2016;9:210-19. doi: 10.1016/j. redox.2016.08.010.

10.Pietryga M, Dydowicz P, Toboła K, Napierała M, Miechowicz I, Gąsiorowska A, Brązert M, Florek E. Selected oxidative stress biomarkers in antenatal diagnosis as 1114 gestational weeks. Free Radic Biol Med. 2017;108:517-23. doi: 10.1016/j. freeradbiomed.2017.04.020.

11.Karacay O, Sepici-Dincel A, Karcaaltincaba D, Sahin D, Yalvac S, Akyol M, Kandemir O, Altan N. A quantitative evaluation of total antioxidant status and oxidative stress markers in preeclampsia and gestational diabetic patients in 24-36 weeks of gestation. Diabetes Res Clin Pract. 2010;89:231-8. doi: 10.1016/j.diabres.2010.04.015.
12.Damasceno DC, Kiss AC, Sinzato YK, de Campos KE, Rudge MV, Calderon IM, Volpato GT. Maternal-fetal outcome, lipid profile and oxidative stress of diabetic rats neonatally exposed to streptozotocin. Exp Clin Endocrinol Diabetes. 2011;119:408-13. doi: $10.1055 / \mathrm{s}-0030-1269886$.

13.Zhao J, Hakvoort TB, Willemsen AM, Jongejan A, Sokolovic M, Bradley EJ, de Boer VC, Baas F, van Kampen AH, Lamers WH. Effect of hyperglycemia on gene expression during early organogenesis in mice. PLoS One. 2016;11(7):e0158035. doi: 10.1371/ journal.pone.0158035.

14. Moazzen $\mathrm{H}$, Lu X, Ma NL, Velenosi TJ, Urquhart BL, Wisse LJ, Gittenbergerde Groot AC, Feng Q. N-Acetylcysteine prevents congenital heart defects induced by pregestational diabetes. Cardiovasc Diabetol. 2014;13:1-13. doi: 10.1186/14752840-13-46.

15.Wang GF, Dong Q, Bai Y, Yuan J, Xu Q, Cao $C$, Liu $X$. Oxidative stress induces mitotic arrest by inhibiting Aurora A-involved mitotic spindle formation. Free Radic Biol Med. 2017;103:177-87. doi: 10.1016/j. freeradbiomed.2016.12.031.

\section{Correspondence:}

Ercan Yilmaz

Faculty of Medicine, Department of Obstetrics

and Gynecology

Inonu University

Malatya Turkey

ercanyilmazgyn@yahoo.com

Received: Dec 15, 2017

Review: Feb 12, 2018

Accepted: Mar 13, 2018
Conflict of interest: none

Financial source: none
${ }^{1}$ Research performed at Animal Study
Laboratory, Inonu University, Malatya, Turkey. 